\section{Medication Literacy: Why Pharmacists Should Pay Attention}

Pharmaceuticals play a primary role in the management of most diseases, but medicines also account for 1 of the 3 most common types of adverse health-related events in Canada. ${ }^{1}$ These medicationrelated adverse events are "highly" preventable in $37 \%$ of cases ${ }^{1}$ and are often caused by the inappropriate use of medicines, a situation that is linked to a poor understanding of medication instructions and to low levels of health literacy. ${ }^{2-6}$ In Canada, individuals are encouraged to make healthy lifestyle decisions and to collaborate with the medical team in developing and implementing their treatment plans, but 60\% of the adult population lacks the necessary skills to manage their health adequately. ${ }^{7}$ Pharmacists working in the community, in clinics, and in hospitals have a central role in advising patients on what medications to use and how to use them, answering questions on medications, and assessing patients' misunderstandings of treatment regimens; as such, they have a role to play in ensuring patients' understanding of their medication regimens and in ensuring the safe and effective use of medications.

It is well known that patients with low health literacy levels experience great difficulties in accessing the health care system and have poorer health status than patients with higher health literacy levels. ${ }^{4,8}$ For example, patients with low health literacy levels are often unable to name or describe how to use their current medications, have a limited understanding of their medications and the associated side effects, and are often less likely to ask questions of their pharmacists. ${ }^{9} 10$ These difficulties in comprehending medication information have been linked to medication errors, misinterpretation of instructions and/or symptoms, poor medication and treatment adherence, lesser self-care behaviour, worse health outcomes, and more visits to the emergency department. ${ }^{8,10-16}$

Use of the concept of health literacy in the context of pharmacy and medications is not new, but a recent increase in interest has led academics and pharmacists from around the world to use more precise concepts such as "medication literacy", "pharmacy health literacy", and "pharmacotherapy literacy", with or without definition. ${ }^{17-20}$ According to Raynor, the term "medication literacy" was first used in 2005 in the United Kingdom in an effort to improve the quality of information provided to patients and to advocate for shared responsibility between patients and health care providers in the development of information that is suitable for people with low health literacy levels. ${ }^{21}$ Most recently, King and others ${ }^{22}$ surveyed practising pharmacists and academics to formulate a definition of the "pharmacotherapy literacy" concept. On the basis of feedback received from participants, the authors proposed the following definition of pharmacotherapy literacy: "An individual's capacity to obtain, evaluate, calculate, and comprehend basic information about pharmacotherapy and pharmacy related services necessary to make appropriate medication-related decisions, regardless of the mode of content delivery (e.g. written, oral, visual images and symbols)" ${ }^{22}$ This definition appears to be the most complete available thus far.

Although health literacy has been identified as a critical factor affecting communication between health care providers and patients and across the continuum of care, a quick look at the Canadian pharmacy literature and documents developed by national and provincial pharmacy organizations shows a lack of peer-reviewed articles and resources for pharmacists referencing concepts such as "medication literacy", "pharmacotherapy literacy", and "pharmacy health literacy". Moving forward, it is crucial that Canadian pharmacists recognize the health literacy crisis that prevails in Canada and address the medication literacy challenges they may face when dispensing medications or providing drug information and/or counselling to patients. Because pharmacists represent an accessible resource for medication information, they are well situated to assess a patient's medication literacy and to apply medication literacy tools to ensure proper counselling and the responsible use of medicines. ${ }^{23}$ Pharmacists should follow guidelines from the International Pharmaceutical Federation's statement of policy regarding medicines information for patients, ${ }^{24}$ which recommends both educational aids and oral counselling methods to support medication literacy.

Many authors have also recommended literacy-sensitive techniques, such as the "teach-back" technique, the use of motivational interviews, the "Ask Me 3" program, product demonstrations, and provision of well-designed materials written at the fifth to eighth grade levels; these approaches, if used concurrently, have the potential to increase medication comprehension. ${ }^{2,25-29}$ Furthermore, when providing information and handouts to patients, pharmacists should focus on the patients' experience of disease, their desired behaviour, and useful day-to-day drug-related information, as opposed to detailed medical information (see guidance available through the Center for Health Care Strategies Inc; www.chcs.org/). Clear, well-understood pictograms or infographics should be included in the handouts, given that multiple studies have shown the tremendous potential of pictograms in supporting health literacy, if they are well developed and validated..$^{30-38}$

Pharmacy schools have a responsibility to incorporate medication literacy tools into their programs and to become 
involved in training the next generation of pharmacists to become effective communicators. ${ }^{39}$ Interventions to enhance pharmacy students' attitudes when addressing the medication literacy of patients have shown great promise. As highlighted by Baur and Brach, ${ }^{40}$ effective pharmacy interventions to support medication literacy also need to move beyond improving the usability of spoken and written information, to focus on awareness, action, mobilization, and education of pharmacists.

\section{References}

1. Baker GR, Norton PG, Flintoft V, Blais R, Brown A, Cox J, et al. The Canadian Adverse Events Study: the incidence of adverse events among hospital patients in Canada. CMAJ. 2004;170(11):1678-86.

2. Praska JL, Kripalani S, Seright AL, Jacobson TA. Identifying and assisting low-literacy patients with medication use: a survey of community pharmacies. Ann Pharmacother. 2005;39(9):1441-5.

3. Volandes AE, Paasche-Orlow MK. Health literacy, health inequality and a just healthcare system. Am J Bioeth. 2007;7(11):5-10.

4. Berkman N, Sheridan S. Low health literacy and health outcomes: an updated systematic review. Ann Intern Med. 2011;155(2):97-107.

5. Miller MJ. Pharmacy efforts in support of the National Action Plan to Improve Health Literacy. Res Social Adm Pharm. 2013;9(5):497.

6. Dewalt DA, Berkman ND, Sheridan S, Lohr KN, Pignone MP. Literacy and health outcomes: a systematic review of the literature. J Gen Intern Med. 2004;19(12):1228-39.

7. Health literacy in Canada: a healthy understanding 2008. Ottawa (ON): Canadian Council on Learning; 2008.

8. Wolf MS, Feinglass J, Thompson J, Baker DW. In search of "low health literacy": threshold vs. gradient effect of literacy on health status and mortality. Soc Sci Med. 2010;70(9):1335-41.

9. Wolf MS, Davis TC, Tilson HH, Bass PF, Parker RM. Misunderstanding of prescription drug warning labels among patients with low literacy. $\mathrm{Am} \mathrm{J}$ Health Syst Pharm. 2006;63(11):1048-55.

10. Youmans SL, Schillinger D. Functional health literacy and medication use: the pharmacist's role. Ann Pharmacother. 2003;37(11):1726-9.

11. Hope C, Wu J, Tu W, Young J, Murray M. Association of medication adherence, knowledge, and skills with emergency department visits by adults 50 years or older with congestive heart failure. Am J Health Syst Pharm. 2004;61(19):2043-9.

12. Muir KW, Santiago-Turla C, Stinnett SS, Herndon LW, Allingham RR, Challa P, et al. Health literacy and adherence to glaucoma therapy. Am J Ophthalmol. 2006;142(2):223-6.

13. Osborn CY, Paasche-Orlow MK, Davis TC, Wolf MS. Health literacy: an overlooked factor in understanding HIV health disparities. Am J Prev Med. 2007;33(5):374-8

14. Mitchell SE, Sadikova E, Jack BW, Paasche-Orlow MK. Health literacy and 30-day postdischarge hospital utilization. J Health Commun. 2012;17 Suppl 3:325-38.

15. Bains SS, Egede LE. Associations between health literacy, diabetes knowledge, self-care behaviors, and glycemic control in a low income population with type 2 diabetes. Diabetes Technol Ther. 2011;13(3):335-41.

16. Ngoh LN. Health literacy: a barrier to pharmacist-patient communication and medication adherence. J Am Pharm Assoc (2003). 2009;49(5):e132-46; quiz e147-9.

17. Montagne M. Pharmaceutical pictograms: a model for development and testing for comprehension and utility. Res Social Adm Pharm. 2013;9(5): 609-20.

18. Raynor DK. Addressing medication literacy: a pharmacy practice priority. Int J Pharm Pract. 2009;17(5):257-9.

19. Emad H. Addressing medication literacy in diabetic geriatrics. J Diabetes Metab. 2012;3(3):1-3.

20. Sauceda JA, Loya AM, Sias JJ, Taylor T, Wiebe JS, Rivera JO. Medication literacy in Spanish and English: psychometric evaluation of a new assessment tool. J Am Pharm Assoc (2003). 2012;52(6):e231-40.

21. Raynor DK. Medication literacy is a 2-way street. Mayo Clin Proc. 2008; 83(5):520-2.
22. King SR, McCaffrey DJ, Bouldin AS. Health literacy in the pharmacy setting: defining pharmacotherapy literacy. Pharm Pract (Granada). 2011; 9(4):213-20.

23. FIP annual report 2013/14: growing the responsible use of medicines. The Hague (Netherlands): International Pharmaceutical Federation; [cited 2015 Nov 13]. Available from: www.fip.org/annualreport13-14/data/ document.pdf

24. FIP statement of policy: medicines information for patients. The Hague (Netherlands): International Pharmaceutical Federation; 2008 [cited 2015 Nov 13]. Available from: www.fip.org/www/uploads/database_file.php? id=290\&table id

25. O'Neal KS, Crosby KM, Miller MJ, Murray KA, Condren ME. Assessing health literacy practices in a community pharmacy environment: experiences using the AHRQ Pharmacy Health Literacy Assessment Tool. Res Social Adm Pharm. 2013;9(5):564-96.

26. Institute of Medicine (US), Committee on Health Literacy; NeilsenBohlman L, Panzer AM, Kindig DA, editors. Health literacy: a prescription to end confusion. Washington (DC): National Academies Press; 2004 [cited 2015 Mar 18]. Available from: www.ncbi.nlm.nih.gov/pubmed/25009856

27. Schwartzberg JG, Cowett A, VanGeest J, Wolf MS. Communication techniques for patients with low health literacy: a survey of physicians, nurses, and pharmacists. Am J Health Behav. 2007;31 Suppl 1:s96-104.

28. Miller MJ, Abrams MA, McClintock B, Cantrell MA, Dossett CD, McCleeary EM, et al. Promoting health communication between the community-dwelling well-elderly and pharmacists: the Ask Me 3 program. JAm Pharm Assoc (2003). 2008;48(6):784-92.

29. Collum JL, Marcy TR, Stevens EL, Burns CF, Miller MJ. Exploring patient expectations for pharmacist-provided literacy-sensitive communication. Res Social Adm Pharm. 2013;9(5):626-32.

30. Katz MG, Kripalani S, Weiss BD. Use of pictorial aids in medication instructions: a review of the literature. Am J Health Syst Pharm. 2006; 63(23):2391-7

31. Dowse R, Ehlers MS. The evaluation of pharmaceutical pictograms in a low-literate South African population. Patient Educ Couns. 2001; 45(2):87-99.

32. Dowse R, Ehlers MS. The influence of education on the interpretation of pharmaceutical pictograms for communicating medicine instructions. Int J Pharm Pract. 2003;11(1):11-8.

33. Mansoor LE, Dowse R. Effect of pictograms on readability of patient information materials. Ann Pharmacother. 2003;37(7-8):1003-9.

34. Sojourner RJ, Wogalter MS. The influence of pictorials on the comprehension and recall of pharmaceutical safety and warning information. Int J Cogn Ergon. 1998;2(1/2):93-106.

35. Wogalter MS, Kalsher MJ, Racicot BM. The influence of location and pictorials on behavioral compliance to warnings. Proc Hum Factors Ergon Soc Annu Meet. 1992;36(13):1029-33.

36. Ngoh LN. Design, development, and evaluation of visual aids for communicating prescription drug instructions to nonliterate patients in rural Cameroon. Patient Educ Couns. 1997;30(3):257-70.

37. Yin HS, Mendelsohn AL, Fierman A, van Schaick L, Bazan IS, Dreyer BP. Use of a pictographic diagram to decrease parent dosing errors with infant acetaminophen: a health literacy perspective. Acad Pediatr. 2011;11(1):50-7.

38. Katz MG, Kripalani S, Weiss BD. Use of pictorial aids in medication instructions: a review of the literature. Am J Health Syst Pharm. 2006; 63(23):2391-7.

39. Wilcoxen K, King SR. An educational strategy to enhance pharmacy students' attitudes toward addressing health literacy of patients. Curr Pharm Teach Learn. 2013;5(2):85-92.

40. Baur C, Brach C. Pharmacy research on health literacy can contribute to national goals and health care system improvements. Res Social Adm Pharm. 2013;9(5):498-502.

\section{Annie Pouliot, $\mathrm{PhD}$}

Régis Vaillancourt, PharmD

Children's Hospital of Eastern Ontario

Ottawa, Ontario

Competing interests: None declared. 